\title{
POTENCIAL POLUIDOR DE REJEITOS CARBONÍFEROS. I - CARACTERIZAÇÃO QUÍMICA DA ÁGUA DE LIXIVIAÇÃO ${ }^{1}$
}

\author{
POLLUTANT POTENCIAL OF COAL REJECTS . I - CHEMICAL \\ CHARACTERIZATION OF THE LEACHED WATER
}

\author{
Larisa Ho Bech Gaivizzo $^{2}$ Caio Vidor $^{3}$ Marino José Tedesco $^{4}$ Egon Meurer $^{5}$
}

RESUMO

\begin{abstract}
O aumento da produção carbonífera no Rio Grande do Sul para o atendimento da crescente demanda por energia tem proporcionado o acúmulo desordenado de grandes volumes de rejeitos nas áreas de mineração. Esses rejeitos afetam a qualidade da água, do ar e do solo, bem como a vegetação e a fauna, podendo representar elevado comprometimento ambiental para a região. Assim, realizou-se o presente estudo com o objetivo de avaliar a composição química da água de lixiviação proveniente de colunas de PVC em experimento envolvendo diferentes espessuras de solo aplicadas na superfície do rejeito carbonífero, solo em posições de subsuperfície e solo misturado ao rejeito. A água de lixiviação foi coletada em 1993, durante o cultivo de milho e trevo-branco, em 1995, antes e após o cultivo de aveia-preta, e em 1996, após o cultivo de milho. Os dados demonstram que o baixo $\mathrm{pH}$ da água de lixiviação manteve solúvel parte dos elementos provenientes da dissolução do rejeito carbonífero, refletindo-se em elevada condutividade elétrica. Os elementos $\mathrm{S}, \mathrm{Fe}, \mathrm{Mn}, \mathrm{Zn}$, Ni e Pb foram os que ocorreram em maiores concentrações na água de lixiviação, com potencial poluidor dos recursos hídricos.
\end{abstract}

Palavras-chave: acidificação, água de lixiviação, solubilização de metais.

\section{SUMMARY}

The quality of water, air, soil, vegetation and fauna have been affected by the increasing explotation of coal and consequently increasing of rejects that have been accumulated, causing adverse effects on the environment of a region in Rio Grande do Sul State, Brazil. An experiment was carried out to evaluate the chemical composition of leached water as a consequence of soil layers with different thickness disposed on PVC columns in the surface of coal rejects, in subsurface positions, and soil mixed with rejects. The leachates were collected in 1993, during (Zea mays L.) corn and white clover (Trifolium repens $L$.) growth; in 1995, before and after oat growth (Avena strigosa L.); and in 1996 after corn growth. Leached water had a high electrical conductivity value because its low $\mathrm{pH}$ maintened in solution part of the elements dissolved from the residues. High concentrations of $\mathrm{S}, \mathrm{Fe}, \mathrm{Mn}, \mathrm{Zn}, \mathrm{Ni}$ and $\mathrm{Pb}$ were detected in the leached water that can be considered as a potential pollutant of natural water streams.

Key words: acidification, leached water, metal solubilization.

\section{INTRODUÇÃO}

O aumento da produção carbonífera para o atendimento da demanda por energia tem proporcionado o acúmulo de rejeitos nas áreas de mineração. $\mathrm{O}$ rejeito origina-se nas plantas de beneficiamento, nos quais 30 a $60 \%$ do material minerado é refugado durante os processos de fracionamento, separação e limpeza do carvão (STEWART \& DANIELS, 1992). Os rejeitos carboníferos constituem-se de rocha fragmentada, compostos sulfurados e carvão de baixa qualidade. Os compostos sulfurados encontram-se principalmente na forma de pirita $\left(\mathrm{FeS}_{2}\right)$ e outros sulfetos, cuja exposição às condições oxidantes do

${ }^{1}$ Parte da dissertação de mestrado em Ciência do Solo do primeiro autor, apresentada à Faculdade de Agronomia da Universidade Federal do Rio Grande do Sul (UFRGS), Porto Alegre, RS, em junho de 1997. Trabalho financiado pelo CIAMB/CNPq

${ }^{2}$ Engenheiro Agrônomo, atualmente cursando Doutorado em Ciência do Solo na Faculdade de Agronomia da UFRGS. Bolsista da

CAPES. R. Gonçalves Dias, 603/305, 90.130-061, Porto Alegre, RS. E-mail: larisaho@zipmail.com.br. Autor para correspondência.

${ }^{3}$ Professor Adjunto (aposentado) do Departamento de Solos da Faculdade de Agronomia da UFRGS

${ }^{4}$ Professor Titular do Departamento de Solos da Faculdade de Agronomia da UFRGS. Bolsista do CNPq.

${ }^{5}$ Professor Adjunto do Departamento de Solos da Faculdade de Agronomia da UFRGS. Bolsista do CNPq. 
meio é responsável pela formação de grande quantidade de ácido sulfúrico. Segundo ROGOWSKI et al. (1977), são gerados 4 mols de $\mathrm{H}^{+}$ para cada mol de pirita consumido nas reações de oxidação.

O ácido sulfúrico intemperiza parte dos minerais no rejeito, adicionando grande quantidade de íons à solução (TORREY, 1978). Em períodos de intensa precipitação pluviométrica, a água de escorrimento superficial ou a percolada através do rejeito possui baixo $\mathrm{pH}$, elevados teores de ferro e sulfatos e, freqüentemente, concentrações elevadas de metais-traço (SPOTTS \& DOLLHOPF, 1992). Os elementos $\mathrm{Cu}, \mathrm{Ni}, \mathrm{Zn}, \mathrm{Cd}$ e $\mathrm{Pb}$ normalmente encontram-se associados aos sulfetos, que são solubilizados durante as reações de oxidação (McBRIDE, 1994). A elevada concentração de íons $\mathrm{H}^{+}$na água de lixiviação favorece a solubilidade dos metais pesados, que podem comprometer a qualidade dos recursos hídricos e atingir níveis de toxidade às plantas e aos animais (BLEVINS et al., 1970; MACHADO, 1985).

De acordo com DANIELS (1996), a ocorrência de drenagem ácida constitui-se no principal impacto das áreas de exploração mineral ao ambiente. A fim de subsidiar os trabalhos de recuperação e minimizar o potencial poluidor dessas áreas, desenvolveu-se o presente estudo com o objetivo de avaliar o efeito da disposição de camadas de solo com diferentes espessuras sobre o rejeito carbonífero e em posições de subsuperfície, e do solo misturado ao rejeito sobre a composição química da água de lixiviação.

\section{MATERIAL E MÉTODOS}

O experimento foi iniciado em 1993, no Departamento de Solos da Faculdade de Agronomia, da URFGS. As unidades experimentais foram constituídas por tubos cilíndricos de PVC com $30 \mathrm{~cm}$ de diâmetro e $60 \mathrm{~cm}$ de altura, sendo consideradas como colunas de lixiviação. Os tratamentos consistiram de camadas (separadas por tela plástica) de solo (S) e de rejeito carbonífero (RC), com as seguintes espessuras e disposição a partir da superfície: 1) $60 \mathrm{~cm}$ de solo $(\mathrm{S})$; 2) $60 \mathrm{~cm}$ de rejeito carbonífero (RC); 3) $60 \mathrm{~cm}$ de $\mathrm{RC}+$ adubo
PK; 4) $10 \mathrm{~cm}$ de $\mathrm{S}+1 \mathrm{~cm}$ de calcário $+49 \mathrm{~cm}$ de RC 5) $5 \mathrm{~cm}$ de $\mathrm{S}+55 \mathrm{~cm}$ de $\mathrm{RC}$; 6) $10 \mathrm{~cm}$ de $\mathrm{S}+50 \mathrm{~cm} \mathrm{de}$ $\mathrm{RC}$; 7) $15 \mathrm{~cm}$ de $\mathrm{S}+45 \mathrm{~cm}$ de $\mathrm{RC}$; 8) $10 \mathrm{~cm}$ de $\mathrm{S}+$ $45 \mathrm{~cm}$ de mistura $1 \mathrm{~S}: 1 \mathrm{RC}+5 \mathrm{~cm}$ de $\mathrm{S} ; 9) 10 \mathrm{~cm}$ de $\mathrm{S}$ $+20 \mathrm{~cm}$ de $\mathrm{RC}+5 \mathrm{~cm}$ de $\mathrm{S}+20 \mathrm{~cm}$ de $\mathrm{RC}+5 \mathrm{~cm}$ de $\mathrm{S}$; 10) $10 \mathrm{~cm}$ de $\mathrm{S}+45 \mathrm{~cm}$ de $\mathrm{RC}+5 \mathrm{~cm}$ de $\mathrm{S}$; 11) $10 \mathrm{~cm}$ de $\mathrm{S}+40 \mathrm{~cm}$ de $\mathrm{RC}+10 \mathrm{~cm}$ de $\mathrm{S} ; 12) 10 \mathrm{~cm}$ de $\mathrm{S}+35 \mathrm{~cm}$ de $\mathrm{RC}+15 \mathrm{~cm}$ de $\mathrm{S}$.

$\mathrm{O}$ delineamento experimental adotado foi o de blocos completos casualizados com doze tratamentos e três repetições. Utilizou-se a camada superficial $(0-20 \mathrm{~cm})$ de um Argissolo VermelhoAmarelo (EMBRAPA, 1999), coletado na Estação Experimental Agronômica da UFRGS em Eldorado do Sul, RS. Na instalação do experimento, o solo e o rejeito carbonífero (somente o tratamento 3 ) foram adubados com $390 \mathrm{mg} \mathrm{kg}^{-1}$ de $\mathrm{K}$ e $500 \mathrm{mg} \mathrm{kg}^{-1}$ de $\mathrm{P}$ nas formas de $\mathrm{KH}_{2} \mathrm{PO}_{4}$ e $\mathrm{NaH}_{2} \mathrm{PO}_{4}$. A acidez do solo foi corrigida para $\mathrm{pH}$ 6,5 com uma mistura de carbonato de cálcio e de magnésio na proporção de 2:1, em quantidade equivalente a $4 \mathrm{Mg} \mathrm{ha}^{-1}$. O rejeito carbonífero foi coletado em pilhas de rejeitos existentes na área de recomposição topográfica da mina explorada pela COPELMI, no município de Butiá, RS. A caracterização química do solo e do rejeito, conforme TEDESCO et al. (1995), é apresentada na tabela 1 .

Em 1993, durante o cultivo de milho (Zea mays L.) e de trevo-branco (Trifolium repens $\mathbf{L}_{\text {.) }}$, foram feitas coletas da água de lixiviação no período de agosto a setembro. Neste período, as colunas permaneceram em ambiente aberto, e as lixiviações foram ocasionadas por precipitações pluviométricas acumuladas (amostra composta) em três períodos de coleta $(70,558$ e 60mm). Em 1994, as colunas
Tabela 1 - Caracterização química do solo (S) e do rejeito carbonífero (RC) utilizados no experimento.

\begin{tabular}{|c|c|c|c|c|}
\hline Característica & Extração & Determinação & S & $\mathrm{RC}$ \\
\hline pH em água & 1:1 solo:água & potenciometria & 4,8 & 3,2 \\
\hline $\mathrm{P}$ disponível $\left(\mathrm{mg} \mathrm{dm}^{-3}\right)$ & $\mathrm{HC} \ell 0,05 \mathrm{~mol} . \ell^{-1}+\mathrm{H}_{2} \mathrm{SO}_{4} 0,025 \mathrm{~mol} \cdot \ell^{-1}$ & colorimetria & 4 & 12 \\
\hline $\mathrm{K}$ disponível $\left(\mathrm{mg} \mathrm{dm}^{-3}\right)$ & $\mathrm{HC} \ell 0,05 \mathrm{~mol} . \ell^{-1}+\mathrm{H}_{2} \mathrm{SO}_{4} 0,025 \mathrm{~mol} \cdot \ell^{-1}$ & colorimetria & 104 & 72 \\
\hline Matéria orgânica $\left(\mathrm{g} \mathrm{dm}^{-3}\right)$ & Solução sulfo-crômica & EAA $^{1 /}$ & 22 & 100 \\
\hline $\mathrm{Al}$ trocável $\left(\mathrm{cmol}_{\mathrm{c}} \mathrm{dm}^{-3}\right)$ & $\mathrm{KC} \ell=1 \mathrm{~mol} \cdot \ell^{-1}$ & EAA & 1,5 & 7,3 \\
\hline Ca trocável $\left(\mathrm{cmol}_{\mathrm{c}} \mathrm{dm}^{-3}\right)$ & $\mathrm{KC} \ell 1 \mathrm{~mol} \cdot \ell^{-1}$ & titulação & 1,2 & 16,8 \\
\hline Mg trocável $\left(\mathrm{cmol}_{\mathrm{c}} \mathrm{dm}^{-3}\right)$ & $\mathrm{KC} \ell 1 \mathrm{~mol} \cdot \ell^{-1}$ & titulação & 0,9 & 2,1 \\
\hline $\mathrm{H}+\mathrm{Al}$ extraível $\left(\mathrm{cmol}_{\mathrm{c}} \mathrm{dm}^{-3}\right)$ & solução SMP & potenciometria & 3,1 & 10,2 \\
\hline Fe extraível $\left(\mathrm{g} \mathrm{dm}^{-3}\right)$ & oxalato de amônio $0,2 \mathrm{~mol} \cdot \ell^{-1}$ & EAA & 1,2 & 4,2 \\
\hline S extraível $\left(\mathrm{mg} \mathrm{dm}^{-3}\right)$ & fosfato de $\mathrm{Ca}\left(500 \mathrm{mg} \cdot \ell^{-1} \mathrm{de} \mathrm{P}\right)$ & turbidimetria & 14 & 1789 \\
\hline Zn extraível ( $\left.\mathrm{mg} \mathrm{dm}^{-3}\right)$ & $\mathrm{HC} \ell 0,1 \mathrm{~mol} \cdot \ell^{-1}$ & EAA & 1,1 & 8,4 \\
\hline Cu extraível $\left(\mathrm{mg} \mathrm{dm}^{-3}\right)$ & $\mathrm{HC} \ell 0,1 \mathrm{~mol} \cdot \ell^{-1}$ & EAA & 0,8 & 0,8 \\
\hline B extraível $\left(\mathrm{mg} \mathrm{dm}^{-3}\right)$ & água quente & colorimetria & 0,7 & 0,5 \\
\hline Mn trocável $\left(\mathrm{mg} \mathrm{dm}^{-3}\right)$ & $\mathrm{KC} \ell 1 \mathrm{~mol} . \ell^{-1}$ & EAA & 31 & 122 \\
\hline Teor de argila $\left(\mathrm{g} \mathrm{kg}^{-1}\right)$ & dispersão com $\mathrm{NaOH}$ & densimetria & 24 & 10 \\
\hline
\end{tabular}

${ }^{1 / E A A}$ (espectrofotometria de absorção atômica, atomização por chama de ar-acetileno).

Ciência Rural, v. 32, n. 5, 2002. 
permaneceram cobertas por lona plástica. O experimento foi reiniciado em 1995 e conduzido em ambiente coberto (com controle do suprimento de água), sendo que a coleta do lixiviado ocorreu em julho e novembro, antes e depois do cultivo de aveia-preta (Avena strigosa L.), e, em outubro de 1996, após o cultivo de milho.

Durante os cultivos de aveia e milho, em 1995 e 1996, respectivamente, foram feitas irrigações diárias e suplementações semanais com $\mathrm{N}$, $\mathrm{P}, \mathrm{K}$, como solução nutritiva, para atingir as concentrações finais de $400 \mathrm{mg}$ de $\mathrm{N}, 80 \mathrm{mg}$ de $\mathrm{P}$ e $600 \mathrm{mg}$ de $\mathrm{K}$ suficientes para um rendimento aproximado de $20 \mathrm{~g}$ por vaso de matéria seca de aveia e $400 \mathrm{mg}$ de $\mathrm{N}, 80 \mathrm{mg}$ de $\mathrm{P}$ e $920 \mathrm{mg}$ de $\mathrm{K}$ suficientes para um rendimento aproximado de $50 \mathrm{~g}$ por vaso de matéria seca de milho.

A água de lixiviação foi coletada em garrafões de vidro conectados na parte inferior das colunas. Em julho de 1995, adicionaram-se uniformemente à superfície dos vasos três litros de água nos tratamentos $1,4,5,6,7,8,9,10,11 \mathrm{e}$ 12 e $6 \ell$ nos tratamentos 2 e 3 , e em novembro de 1995, adicionaram-se dois litros em todos os tratamentos. Os lixiviados foram coletados $72 \mathrm{~h}$ após a adição de água. Em outubro de 1996, adicionaram-se três litros nos tratamentos 1, 4, 5, $6,7,8,9,10,11$ e 12 e $4 \ell$ nos tratamentos 2 e 3 , e a coleta dos lixiviados foi realizada 144 h após a adição de água.

Após a medição do volume do lixiviado,

coletaram-se amostras de $300 \mathrm{~m} \ell$ de cada coluna para a determinação imediata de $\mathrm{pH}$, condutividade elétrica (CE), Na e K (diretamente na amostra), dos teores totais de $\mathrm{N}, \mathrm{P}, \mathrm{Ca}$ e $\mathrm{Mg}$ (digestão ácida com $\mathrm{H}_{2} \mathrm{SO}_{4}-\mathrm{H}_{2} \mathrm{O}_{2}$ ) e de $\mathrm{S}, \mathrm{Fe}, \mathrm{Cu}, \mathrm{Zn}, \mathrm{Mn}, \mathrm{Ni}, \mathrm{Pb}$ e $\mathrm{Cd}$ (digestão ácida com $\mathrm{HNO}_{3}-\mathrm{HClO}_{4}$ ). Todas as determinações seguiram metodologia descrita por TEDESCO et al. (1995).

Foi utilizada a análise de variância, complementada por teste de comparações múltiplas (Tukey) a $5 \%$ de probabilidade de erro para a comparação das médias. Maiores detalhes sobre a instalação e a condução do experimento podem ser encontrados em GAIVIZZO (1997).

\section{RESULTADOS E DISCUSSÃO}

$\mathrm{O}$ pH da água de lixiviação (AL) foi significativamente menor nos tratamentos com rejeito carbonífero (RC) (Figura 1). Os valores de $\mathrm{pH}$ nesses tratamentos oscilaram entre 0,0 e 2,3 durante o período experimental. Esses resultados devem-se à oxidação da pirita, com formação de ácido sulfúrico, resultando em elevadas concentrações de $\mathrm{H}^{+}$na água de lixiviação. Observase a tendência de diminuição da concentração de íons $\mathrm{H}^{+}$na água de lixiviação dos tratamentos 10,11 e 12, que tinham camadas de solo abaixo do rejeito carbonífero, e nos tratamentos 8 e 9 , com mistura (1:1) e camadas alternadas de solo/rejeito. Esse comportamento pode ser devido à correção da acidez do solo para pH 6,5 e sua atuação como um filtro em profundidade, que reteve parte dos íons provenientes do rejeito, e à diminuição do volume de rejeito carbonífero nas colunas de lixiviação.

Comparando-se o tratamento 7 , com $15 \mathrm{~cm}$ de solo na superfície de $45 \mathrm{~cm}$ do rejeito carbonífero, com os tratamentos 8 e 10, que também possuíam $45 \mathrm{~cm}$ de rejeito, constata-se que a utilização de uma camada de solo de cobertura de maior espessura não foi suficiente para limitar a produção de ácido. De acordo com DANIELS (1996), os métodos de redução do fluxo de $\mathrm{O}_{2}$ na pilha de rejeitos através da cobertura com solo e estabelecimento vegetal continuam produzindo a drenagem ácida por décadas ou mais, pois a bactéria Thiobacillus ferrooxidans é capaz de catalisar as reações de oxidação da pirita mesmo em ambientes com baixas concentrações de $\mathrm{O}_{2}$.

No tratamento 1 , com $60 \mathrm{~cm}$ de solo, ocorreu a diminuição progressiva do $\mathrm{pH}$ da água de lixiviação entre os períodos de amostragem, demonstrando que na primeira lixiviação (1993), devido à adição de calcário na instalação do experimento, apenas uma parte dos íons $\mathrm{OH}^{-}$ resultantes da dissolução do carbonato tinha reagido com os íons $\mathrm{H}^{+}$da solução. Observa-se também a acidificação da água de lixiviação dos tratamentos com RC no decorrer do experimento. Isso, provavelmente, ocorreu devido à continuidade das reações de oxidação da pirita, que indica a grande resistência dos sulfetos à oxidação, e à perda de cátions básicos nas primeiras lixiviações. Tal comportamento também foi observado por MASSEY \& BARNHISEL (1972), STEWART $\boldsymbol{e} t$ al. (1993) e SOARES (1995).

A condutividade elétrica (CE) foi bastante afetada pelo rejeito carbonífero (Figura 1). O tratamento 1 , com $60 \mathrm{~cm}$ de solo, apresentou os menores valores de $\mathrm{CE}$, variando de 0,2 a $1,3 \mathrm{dS} \mathrm{m}^{-1}$, em comparação com os tratamentos com rejeito carbonífero, nos quais variou de 11,8 a $116,7 \mathrm{dS} \mathrm{m}^{-1}$ durante o período experimental. $\mathrm{O}$ aumento da $\mathrm{CE}$ se deve à formação de ácido sulfúrico e sua ação sobre os minerais presentes no rejeito, dando origem a uma drenagem ácida com elevada concentração de íons. Da primeira lixiviação (1993) até a segunda (julho de 1995), ocorreu o aumento na CE da AL, 

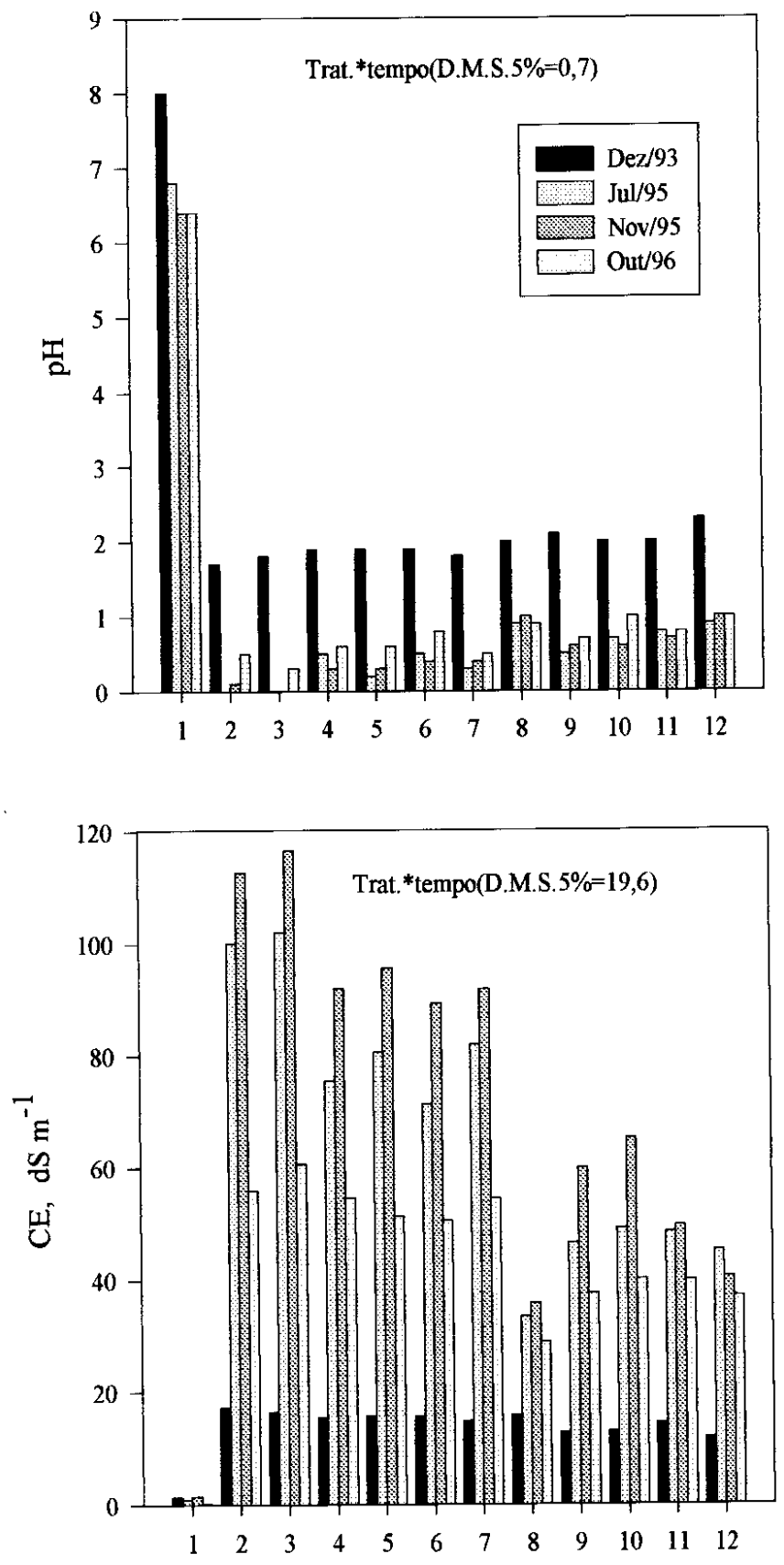

Tratamentos

Figura 1 - Valores de pH e condutividade elétrica (CE) na água de lixiviação na primeira (dez/93), segunda (jul/95), terceira (nov/95) e quarta (out/96) amostragens de colunas com diferentes camadas de solo (S) e rejeito carbonífero (RC): $1-60 \mathrm{~cm} \mathrm{de} S ; 2-60 \mathrm{~cm}$ de $\mathrm{RC} ; 3-60 \mathrm{~cm}$ de $\mathrm{RC}+$ adubo PK; $4-10 \mathrm{~cm}$ de $\mathrm{S}+1 \mathrm{~cm}$ de calcário $+49 \mathrm{~cm}$ de RC ; 5- $5 \mathrm{~cm}$ de $\mathrm{S}+55 \mathrm{~cm}$ de $\mathrm{RC} ; 6-10 \mathrm{~cm}$ de $\mathrm{S}+$ $50 \mathrm{~cm}$ de RC; $7-15 \mathrm{~cm}$ de $\mathrm{S}+45 \mathrm{~cm}$ de $\mathrm{RC} ; 8-10 \mathrm{~cm}$ de $\mathrm{S}+45 \mathrm{~cm}$ de mistura $1 \mathrm{~S}: 1 \mathrm{RC}+5 \mathrm{~cm}$ de $\mathrm{S} ; 9-10 \mathrm{~cm}$ de $\mathrm{S}+20 \mathrm{~cm}$ de RC + $5 \mathrm{~cm}$ de $\mathrm{S}+20 \mathrm{~cm}$ de $\mathrm{RC}+5 \mathrm{~cm}$ de $\mathrm{S} ; 10-10 \mathrm{~cm}$ de $\mathrm{S}+45 \mathrm{~cm}$ de RC $+5 \mathrm{~cm}$ de $\mathrm{S} ; 11-10 \mathrm{~cm}$ de $\mathrm{S}+40 \mathrm{~cm}$ de RC+10cm de $\mathrm{R} ; 12-$ $10 \mathrm{~cm}$ de $\mathrm{S}+35 \mathrm{~cm}$ de $\mathrm{RC}+15 \mathrm{~cm}$ de $\mathrm{S}$.

Ciência Rural, v. 32, n. 5, 2002. 
em função da maior intemperização do rejeito. Observa-se também que, da terceira lixiviação (novembro de 1995) até a quarta (outubro de 1996), ocorreu a redução da CE na maioria dos tratamentos, indicando uma diminuição na velocidade de oxidação da pirita e, conseqüentemente, na solubilização de íons. Essa diminuição pode ser conseqüência da intemperização de partículas ou frações de pirita com maior superfície específica na fase inicial do experimento, resultando em frações de menor superfície específica ao final do período experimental.

Nos tratamentos com rejeito carbonífero, os maiores valores de condutividade elétrica ocorreram nos tratamentos 2 e 3 , com $60 \mathrm{~cm}$ de rejeito carbonífero. Já os menores valores corresponderam aos tratamentos 10, 11 e 12, com camadas de solo abaixo do rejeito, e aos tratamentos 8 e 9, com solo misturado e intercalado ao rejeito. Isso ocorre devido à retenção pelo solo de parte dos íons liberados durante a solubilização dos componentes do rejeito, o que diminui suas concentrações na água de lixiviação (Figura 1).

As concentrações de $\mathrm{Fe}$ e $\mathrm{S}$ foram significativamente maiores nos tratamentos com rejeito carbonífero do que no tratamento 1 , contendo apenas solo corrigido (Figura 2). A principal fonte de $\mathrm{Fe}$ e $\mathrm{S}$ na água de lixiviação é a oxidação da pirita. Segundo MOSES et al. (1987), as reações envolvidas promovem a formação de uma série de sulfatos de ferro solúveis e ácido sulfúrico. A concentração de $\mathrm{Fe}$ na água de lixiviação dos tratamentos com rejeito carbonífero variou de 8,3 a $67,8 \mathrm{mg} \cdot \ell^{-1}$, enquanto que a de $\mathrm{S}$ variou de 3,8 a $26,2 \mathrm{~g} \cdot \ell^{-1}$. No tratamento 1 contendo apenas solo, os valores de Fe e $S$ variaram entre 0,002 a $0,93 \mathrm{mg} . \ell^{-1}$ e 0,01 a $0,06 \mathrm{~g} \cdot \ell^{-1}$, respectivamente.

Houve o aumento na concentração de $\mathrm{Fe}$ na amostragem da água de lixiviação de 1993 até 1995, ocorrendo após a diminuição até 1996. Este comportamento está de acordo com os resultados discutidos anteriormente, ou seja, apesar da persistência do baixo $\mathrm{pH}$ durante o período experimental, que evidenciou a continuidade das reações de oxidação da pirita, os dados de condutividade elétrica sugerem a diminuição na velocidade dessas reações. Ressalta-se que os lixiviados dos tratamentos com rejeito carbonífero apresentaram coloração avermelhada durante todo o período experimental. Esse comportamento também foi obtido por STEWART et al. (1993) para o Fe, ao trabalharem com colunas de lixiviação. Ainda segundo os autores, a hidrólise do Fe na coluna de lixiviação pode ter diminuído a mobilização do elemento para a água de lixiviação.
Não houve interação significativa entre os tratamentos e o tempo de amostragem para os valores de S (Figura 3). Contudo, a diminuição na concentração do elemento entre a primeira (1993) e a segunda lixiviação (julho de 1995) parece ter ocorrido devido às perdas de compostos sulfurados e formação de precipitados na parte inferior das colunas de PVC. Deve-se ainda ressaltar que alguns cátions que apresentavam altas concentrações na água de lixiviação proporcionaram a formação de precipitados nas amostras de lixiviados, por ultrapassarem a concentração característica do produto de solubilidade dos compostos por eles formados, e com isso dificultando as análises laboratoriais. A formação desses precipitados também pode ter ocorrido no interior das colunas de PVC, sendo que estes compostos foram possivelmente dissolvidos durante a terceira (novembro de 1995) e quarta lixiviações (outubro de 1996), principalmente nesta última, em que se utilizou um maior volume de água, quando comparado às outras lixiviações. Esse fato, aliado à continuidade das reações de oxidação da pirita, pode ter sido o responsável pelo aumento da concentração de $\mathrm{S}$ da segunda até a quarta lixiviação.

Diversos autores têm relatado que os rejeitos carboníferos são naturalmente desprovidos de $\mathrm{N}$ por constituirem-se basicamente de rocha intemperizada e fragmentos de carvão (DANIELS, 1996). Portanto, as concentrações do elemento na água de lixiviação devem-se a sua presença no solo (2,2\% de matéria orgânica) e, principalmente, à adição via solução nutritiva. Isto é evidenciado quando se observa o aumento nas perdas de $\mathrm{N}$ na quarta lixiviação (outubro de 1996), decorrentes da adição semanal do elemento via solução nutritiva durante o ciclo do milho, que permaneceu 90 dias nos vasos. Os tratamentos 8 e 9 , com solo misturado e em camadas alternadas ao rejeito, apresentaram maior concentração de $\mathrm{N}$ na água de lixiviação. $\mathrm{O}$ tratamento 1, devido ao maior aproveitamento do $\mathrm{N}$ pelas plantas, apresentou a menor concentração do elemento.

As maiores perdas de $\mathrm{P}$ na água de lixiviação ocorreram no tratamento 3 , pois o rejeito carbonífero foi suplementado com P na instalação do experimento (Figura 3). Nesse tratamento, observase que as maiores concentrações de $\mathrm{P}$ ocorreram na primeira lixiviação (1993), declinando na segunda (julho de 1995) e aumentado na terceira lixiviação (novembro de 1995), devido à nova suplementação do elemento via solução nutritiva. Da terceira para a quarta lixiviação (outubro de 1996) novamente ocorreu a diminuição do P na água de lixiviação.

Ciência Rural, v. 32, n. 5, 2002. 

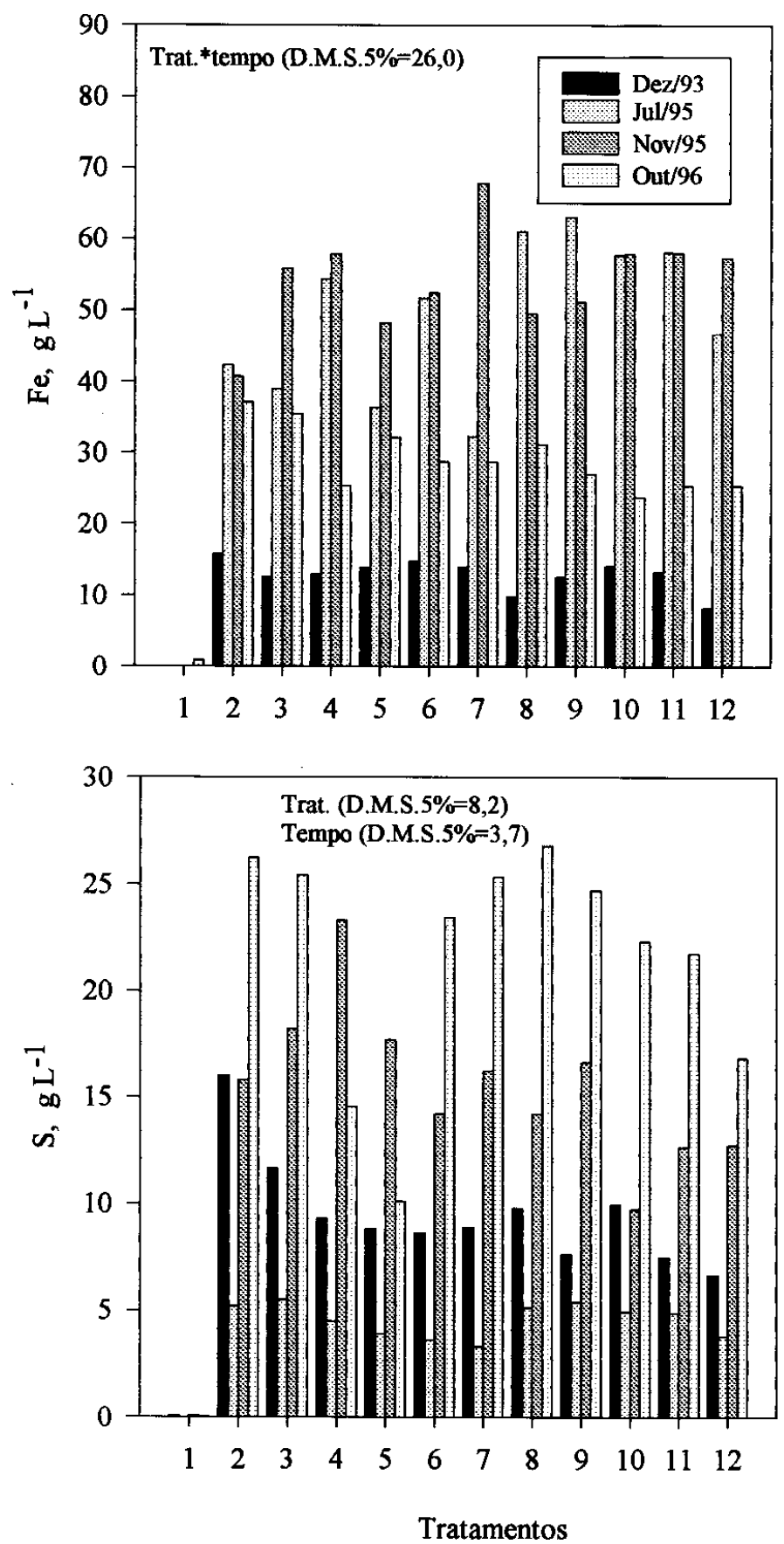

Figura 2 - Concentrações de Fe e S na água de lixiviação, na primeira (dez/93), segunda (jul/95), terceira (nov/95) e quarta (out/96) amostragens de colunas com diferentes camadas de solo $(\mathrm{S})$ e rejeito carbonífero $(\mathrm{RC})$. Idem à figura 1.

Ciência Rural, v. 32, n. 5, 2002. 
Nos demais tratamentos, também houve o aumento do $\mathrm{P}$ na terceira lixiviação, estando diretamente relacionada com as suplementações do elemento efetuadas no período, e a diminuição até a quarta lixiviação. Esses resultados estão de acordo com a diminuição das perdas de Fe na água de lixivição em outubro de 1996 (Figura 2). Segundo DANIELS (1996), à medida que o resíduo carbonífero se intemperiza e oxida, ocorre o aumento da quantidade de óxidos de ferro que possuem reação de adsorção específica com o fósforo, diminuindo sua disponibilidade.

A presença de $\mathrm{K}$ no solo e no resíduo (Tabela 1), a suplementação efetuada na instalação do experimento e a adição do elemento via solução nutritiva explicam as elevadas concentrações de $\mathrm{K}$ na água de lixiviação (Figura 3). Na presença do rejeito carbonífero, como já ocorrera com $\mathrm{N}$ e $\mathrm{P}$, os tratamentos 8 a 12 apresentaram maiores perdas médias de $\mathrm{K}$ que os tratamentos 4 a 7 . Além do maior volume de solo suplementado com $\mathrm{K}$ existente nos tratamentos 8 a 12, deve-se ainda considerar a dissolução dos minerais do RC ocasionada pela ação do ácido sulfúrico que, além de liberarem o $\mathrm{K}$ de suas estruturas, liberam elevadas quantidades de outros cátions que, por efeito de massa e de valência, deslocam o $\mathrm{K}$ dos pontos de troca do solo. $\mathrm{O}$ tratamento 3 , contendo $60 \mathrm{~cm}$ de $\mathrm{RC}$ suplementado com $\mathrm{K}$, também mostrou elevadas perdas de $\mathrm{K}$ na água de lixiviação. Observa-se a diminuição nas perdas de $\mathrm{K}$ da primeira até a terceira lixiviação, seguida de novo aumento na quarta lixiviação. A adição de solução nutritiva durante o ciclo do milho que antecedeu a quarta lixiviação e a intemperização do rejeito carbonífero no período aproximado de um ano entre as duas últimas lixiviações devem ser responsáveis pelas altas concentrações de K encontradas em outubro de 1996.

As concentrações de $\mathrm{Ca}$ e $\mathrm{Mg}$ na água de lixiviação nos tratamentos com rejeito carbonífero foram maiores do que no tratamento 1 (Figura 3). As maiores perdas ocorreram na primeira lixiviação, indicando a dissolução dos carbonatos e a oxidação da pirita. A ocorrência do $\mathrm{Ca}$ e do $\mathrm{Mg}$ na água de lixiviação deve-se à sua presença no rejeito carbonífero e à correção do solo com mistura (2:1) de carbonatos de cálcio e de magnésio na instalação do experimento. A lixiviação de cátions básicos no primeiro ciclo de lixiviação de amostras de carvão (Mina do Recreio, Butiá, RS) também foi observada por SPINELLI \& KÄMPF (1996). A utilização de uma camada de carbonato de cálcio e magnésio entre o solo e o rejeito carbonífero no tratamento 4 aumentou a concentração do $\mathrm{Mg}$ na água de lixiviação quando se comparam as médias dos tratamentos ao longo do tempo. Para o Ca, verificase que, na primeira lixiviação, o tratamento 12 obteve a maior concentração do elemento na água de lixiviação, provavelmente devido à maior espessura da camada subsuperficial de solo $(15 \mathrm{~cm})$.

A concentração de $\mathrm{Mn}$ nos lixiviados foi maior nos tratamentos com rejeito carbonífero (Figura 4). Ao longo do período experimental, verifica-se a diminuição de sua concentração na água de lixiviação desses tratamentos, provavelmente por ter sido intensamente mobilizado já na primeira lixiviação, devido à sua presença no rejeito carbonífero (Tabela 1) e solubilidade em $\mathrm{pH}$ ácido (STEWART et al.,1993).

As lixiviações de $\mathrm{Cu}, \mathrm{Zn}, \mathrm{Cd}$ e $\mathrm{Ni}$ foram maiores nos tratamentos com rejeito carbonífero (Figura 4). A concentração desses elementos aumentou da primeira lixiviação (dezembro de 1993) até a terceira (novembro de 1995), seguida de uma diminuição na quarta lixiviação (outubro de 1996). Considerando-se que a concentração de Fe na água de lixiviação pode ser utilizada como parâmetro indicador das reações de oxidação da pirita (PUGH et al., 1984) e que o $\mathrm{Cu}, \mathrm{Zn}, \mathrm{Cd}$ e $\mathrm{Ni}$ ocorrem no carvão mineral normalmente associado à pirita e a outros sulfetos (McBRIDE, 1994; DANIELS, 1996), verifica-se que a oscilação desses elementos está de acordo com a variação do Fe, confirmando que a velocidade máxima da reação de oxidação da pirita ocorreu em novembro de 1995 , com diminuição gradual até outubro de 1996. Entre os elementos analisados, o $\mathrm{Zn}$ lixiviou em grande quantidade, fato também observado por outros pesquisadores (MASSEY \& BARNHISEL, 1972; MACHADO, 1985; SOARES, 1995). Portanto, a redução na CE (Figura 2), em outubro de 1996, esteve associada à menor concentração de $\mathrm{Zn}, \mathrm{Fe}$, $\mathrm{Mn}, \mathrm{Cu}, \mathrm{Cd}$ e Ni. As perdas de $\mathrm{Pb}$ também apresentaram essa tendência; no entanto, verifica-se que a concentração do elemento na água de lixiviação aumentou da segunda (julho de 1995) a terceira, provavelmente devido à sua presença em outros minerais, além dos sulfetos.

\section{CONCLUSÕES}

O baixo pH da água de lixiviação mantém solúvel parte dos elementos provenientes da dissolução do rejeito carbonífero, refletindo-se em elevada condutividade elétrica. A utilização de camadas de solo em posições de subsuperfície e solo misturado ao rejeito atenua a concentração de íons $\mathrm{H}^{+}$e a condutividade elétrica na água de lixiviação. Os elementos $\mathrm{S}, \mathrm{Fe}, \mathrm{Mn}, \mathrm{Zn}$, Ni e $\mathrm{Pb}$ são os que ocorreram em maiores concentrações na água de 

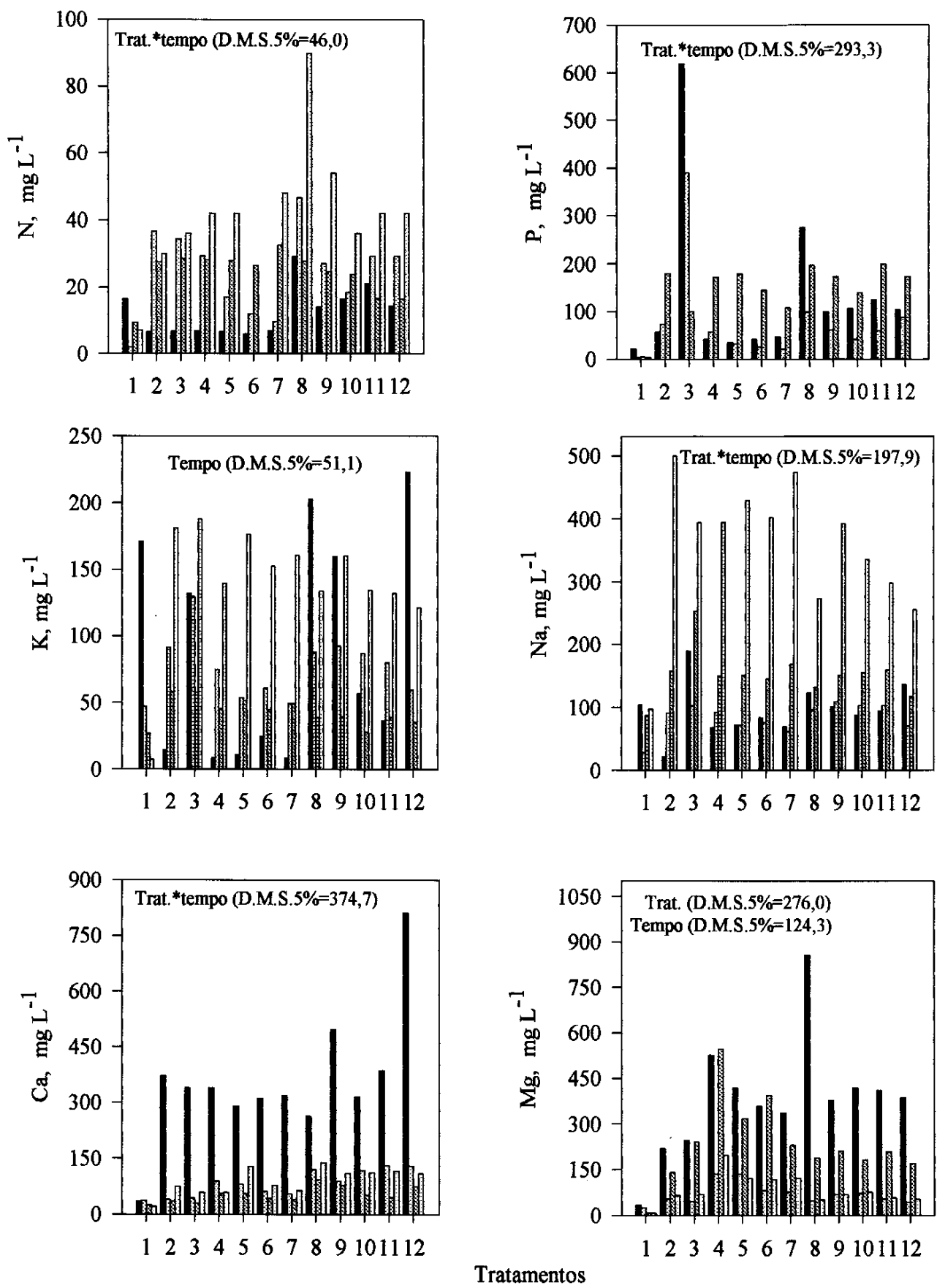

Tratamentos

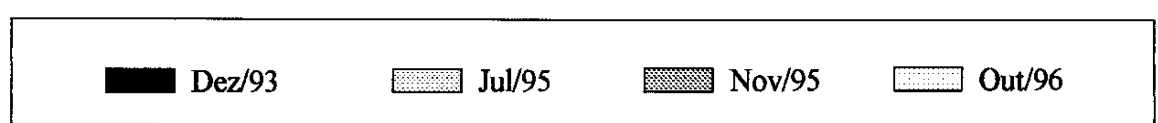

Figura 3 - Concentrações de N, P, K, Na, Ca e Mg na água de lixiviação, na primeira (dez/93), segunda (jul/95), terceira (nov/95) e quarta (out/96) amostragens de colunas com diferentes camadas de solo (S) e rejeito carbonífero (RC). Idem à figura 1.

Ciência Rural, v. 32, n. 5, 2002. 

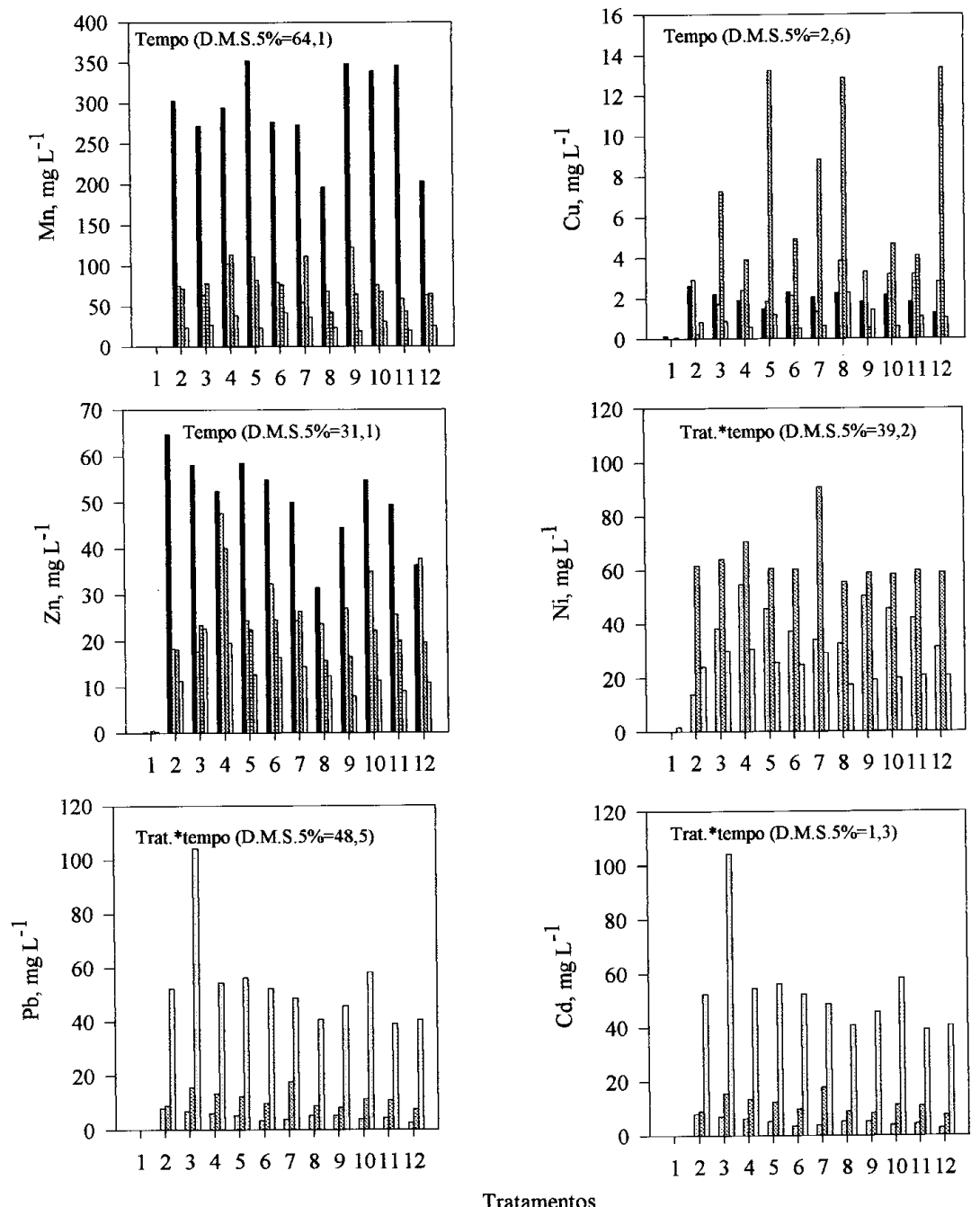

Tratamentos

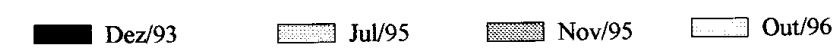

Figura 4 - Concentrações de $\mathrm{Mn}, \mathrm{Cu}, \mathrm{Zn}, \mathrm{Cd}, \mathrm{Pb}$, e Ni na água de lixiviação, na primeira (dez/93), segunda (jul/95), terceira (nov/95) e quarta (out/96) amostragens de colunas com diferentes camadas de solo (S) e rejeito carbonífero (RC). Idem à figura 1.

lixiviação dos tratamentos com rejeito carbonífero. A camada de solo de cobertura de maior espessura $(15 \mathrm{~cm})$ não foi suficiente para reduzir o fluxo de oxigênio e água no rejeito carbonífero e para limitar a produção de ácido.

\section{REFERÊNCIAS BIBLIOGRÁFICAS}

BLEVINS, R.L., BAILEY, H.A., BALLARD, G.E. The effect of acid mine water on flood plains soils in the Western Kentucky coalfields. Soil Science, Baltimore, v.110, n.3, p.191-196, 1970.
DANIELS, W.L. Manipulating the chemical properties of mine soils and mining wastes. In: O SOLO NOS GRANDES DOMÍNIOS MORFOCLIMÁTICOS DO BRASIL E O DESENVOLVIMENTO SUSTENTADO, Viçosa, 1995. Anais... Viçosa : SBCS, UFV, DPS, 1996. p.867-897.

EMBRAPA. Sistema Brasileiro de Classificação de Solos Brasília : Embrapa Produção de Informação; Rio de Janeiro: Embrapa Solos, 1999. 412p.

GAIVIZZO, L.H.B. Potencial poluidor de solo e água por rejeitos carboníferos. Porto Alegre, 1997. 145p. Dissertação (Mestrado em Ciência do Solo) - Programa de Pós-graduação em Ciência do Solo, Universidade Federal do Rio Grande do Sul, 1997. 
MACHADO, J.L.F. Mineração de carvão: contaminação e vulnerabilidade dos mananciais. In: SIMPÓSIO SULBRASILEIRO DE GEOLOGIA, 2., 1985, Florianópolis. Anais... Florianópolis : UFSC, 1985. p.539-551.

MASSEY, H.F., BARNHISEL, R.I. Copper, nickel and zinc released from acid coal mine spoil materials of eastern kentucky. Soil Science, Baltimore, v.113, n.3, p.207-212, 1972.

McBRIDE, M.B. Environmental chemistry of soils. New York: Oxford University, 1994. 395p.

MOSES, C.O., KIRK, N.D., HERMAN, J.S., et al. Aqueous pirite oxidation by dissolved oxygen and by ferric iron. Geochimica et Cosmochimica Acta, New York, v.51, p.1561-1571, 1987.

PUGH, C.E., HOSSNER, L.R., DIXON, J.B. Oxidation rate of iron sulfides as affected by surface area, morphology, oxygen concentration, and autotrophic bacteria. Soil Science, Baltimore, v.137, n.5, p.309-314, 1984.

ROGOSWSKI, A.S., PIONKE, H.B., BROYAN, J.G. Modeling the impact of stripmining and reclamation processes on quality and quantity of water in mined area: a review. Journal of Environmental Quality, Madison, v.16, n.3, p.237-244, 1977.

SOARES, E.R. Mobilidade de metais pesados em materiais provenientes do complexo carboenergético de Candiota -
RS. Viçosa, 1995. 58 p. Dissertação (Mestrado em Ciência do Solo) - Universidade Federal de Viçosa, 1995.

SPINELLI, L.F.P., KÄMPF, N. Adequação do estéril para a composição do solo construído em áreas de mineração de carvão. In: SIMPÓSIO INTERNACIONAL DE QUALIDADE AMBIENTAL, Porto Alegre, 1996. Artigos Técnicos... Porto Alegre : PUC, 1996. p.78-81.

SPOTTS, E., DOLLHOPF, J. Evaluation of phosphate materials for controls of acid production in pyritic mine overburden. Journal of Environmental Quality, Madison, v.21, n.4, p.627-634, 1992.

STEWART, B.R., DANIELS, W.L. Physical and chemical propierties of coal refuse from southwest virginia. Journal of Environmental Quality, Madison, v.21, n.4, p.635-642, 1992.

STEWART, B.R., JACKSON, M.L., DANIELS, W.L. Utilization of fly ash as an amendment for coal refuses. In: POWELL RIVER PROJECT SYMPOSIUM WISE, VA, 1993, Wise. Proceedings... Wise : Virginia Polytechnic Institute, 1993. P.816-820

TEDESCO, M.J., GIANELlO, C., BISSANI, C.A., $\boldsymbol{e} \boldsymbol{t} \boldsymbol{a l}$. Análises de solos, plantas e outros materiais. 2.ed. Porto Alegre : Departamento de Solos,UFRGS, 1995. 174p. (Boletim Técnico, 5).

TORREY, S. Trace contaminants of coal. Park Ridge : Napes Data Corporation, 1978. 249p.

Ciência Rural, v. 32, n. 5, 2002. 